\title{
PROGRAMMABLE CURRENT-CONVEYOR-BASED VOLTAGE-MODE FILTER WITH SINGLE INPUT AND FIVE OUTPUTS
}

\author{
MUHAMMAD TAHER ABUELMA'ATTI AND AZHAR QUDDUS \\ King Fahd University of Petroleum and Minerals, Box 203, Dhahran 31261, Saudi Arabia
}

(Received January 24, 1995; in final form April 3, 1995)

A new universal voltage-mode active-filter with single input and five outputs is presented. The parameters of the proposed filter are programmable and the filter uses grounded capacitors and resistors. The proposed circuit can simultaneously realize lowpass, highpass, bandpass, allpass, and notch biquadratic filter functions and enjoys low temperature sensitivities.

\section{INTRODUCTION}

At present, there is a growing interest in designing universal current-mode and voltage-mode active filters. Thus, a number of circuit realizations, for universal current-mode and voltage-mode filters, using current-conveyors or operationaltransconductance-amplifiers (OTAs) were proposed [1-17]. A critical study shows that while some of the proposed circuits use grounded resistors and capacitors [1-6,11-13], other circuits use floating resistors and/or capacitors [7-10,15-17]. The majority of the proposed circuits can realize all the basic biquadratic filter functions, that is, lowpass, highpass, bandpass, allpass and notch. However, in most of the circuits, this can not be achieved simultaneously. Moreover, while the filter parameters in current-conveyor-based circuits are not programmable, in OTAbased circuits these parameters are programmable. This is attributed to the dependence of the OTA-transconductance $\left(g_{m}\right)$ on the auxiliary bias-current $I_{A B C}$. However, because the auxiliary-bias-current is temperature-dependent, the parameters of the resulting active-filter structures suffer from relatively high temperature sensitivities.

As an illustrative example, consider the circuit proposed by Chang [1]. While the circuit can simultaneously realize lowpass, highpass, and bandpass functions, to obtain an allpass function it is necessary to connect the three output currents. Similarly, to obtain a notch function it is necessary to connect the highpass and the lowpass output currents. Thus, the five basic filter functions can not be realized simultaneously. While the circuit has the advantage of using grounded resistors and capacitors, its parameters are not programmable.

It is the major intention of this paper to explore the feasibility of designing programmable universal filters with relatively low temperature sensitivities. Also, it would be attractive for integration if a proposed implementation can be realized using grounded resistors and capacitors while enjoying high input impedance and independent control of the filter parameters. 


\section{PROPOSED CIRCUIT}

The proposed circuit is shown in Fig. 1. Using the standard notation, the characteristics of the current conveyors can be described by $i_{x}= \pm i_{z}, i_{y}=0, v_{x}=v_{y}$ for the CCII \pm and $i_{o}=g_{m}\left(v_{+}-v_{-}\right)$for the OTA, where $g_{m}=I_{A B C} / 2 V_{T}$ is the transconductance of the OTA, $I_{A B C}$ is the auxiliary bias-current of the OTA, $V_{T}=$ $k T / q$ is the thermal voltage, $k$ is the Boltzman constant, $T$ is the temperature, and $v_{+}$and $v_{-}$are the input voltages of the OTA. Routine analysis of the circuit yields the following transfer functions

$\frac{V_{B P F}}{V_{i}}=\frac{-\left(g_{m} / C_{1}\right) s}{s^{2}+s / C_{1} R_{1}+g_{m} / C_{1} C_{2} R_{1}}$

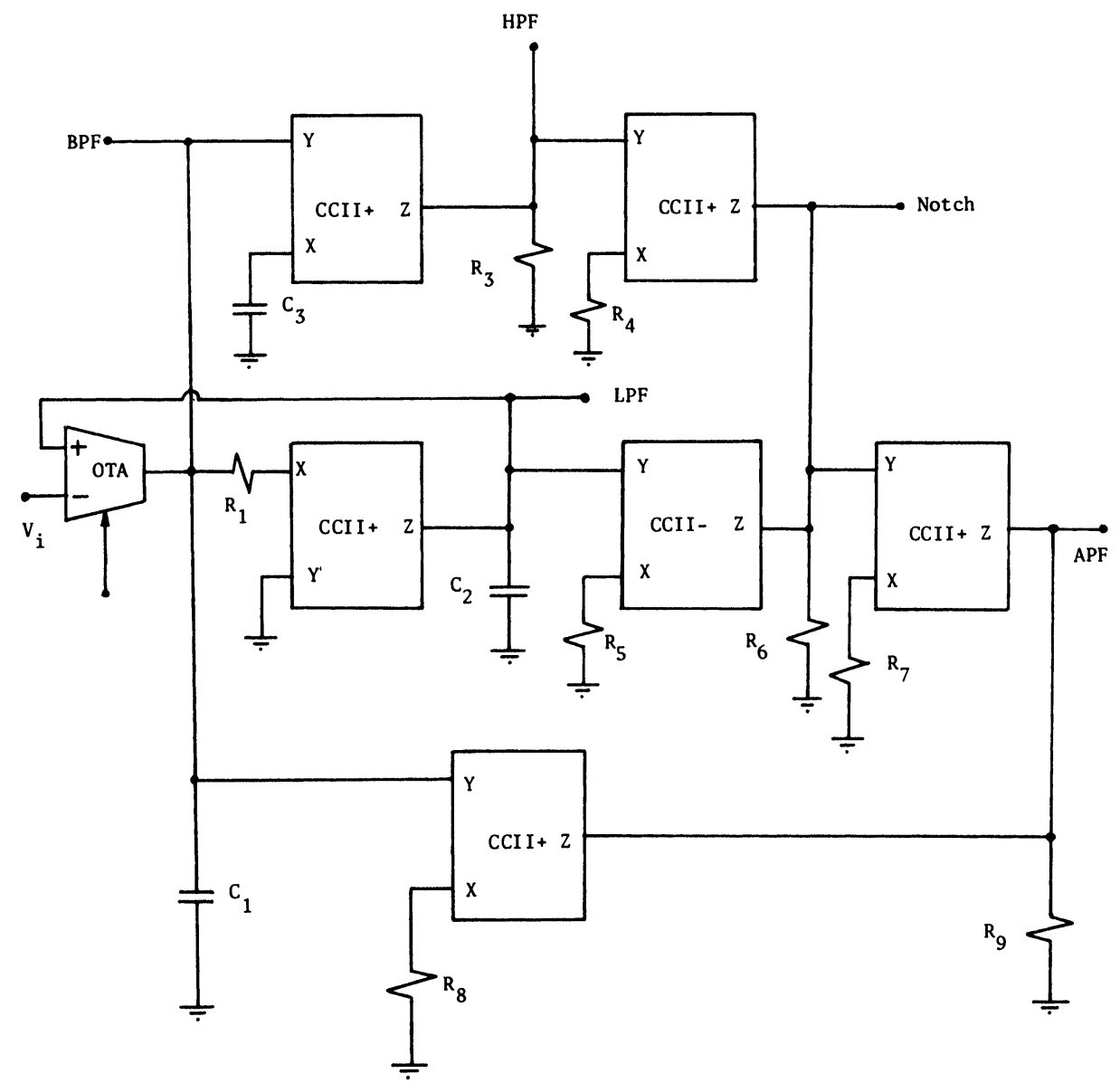

FIGURE 1 Proposed structure for realizing voltage-mode lowpass, highpass, bandpass, notch and allpass filters. 
$\frac{V_{L P F}}{V_{i}}=\frac{g_{m} / R_{1} C_{1} C_{2}}{s^{2}+s / C_{1} R_{1}+g_{m} / C_{1} C_{2} R_{1}}$

$\frac{V_{H P F}}{V_{i}}=\frac{s^{2} g_{m} R_{3} C_{3} / C_{1}}{s^{2}+s / C_{1} R_{1}+g_{m} / C_{2} C_{1} R_{1}}$

If we choose $R_{4} / R_{6}=g_{m} R_{3} C_{3} / C_{1}$ and $R_{5}=R_{6}$ then

$\frac{V_{\text {notch }}}{V_{i}}=\frac{\left(s^{2}+g_{m} / C_{1} C_{2} R_{1}\right)}{s^{2}+s / C_{1} R_{1}+g_{m} / C_{1} C_{2} R_{1}}$

And if we choose $g_{m} R_{1}=R_{8} / R_{9}$ and $R_{7}=R_{9}$ then

$\frac{V_{n o t c h}}{V_{i}}=\frac{s^{2}-s / R_{1} C_{1}+g_{m} / C_{1} C_{2} R_{1}}{s^{2}+s / C_{1} R_{1}+g_{m} / C_{1} C_{2} R_{1}}$

Equation (1) corresponds to the transfer function of a bandpass filter, equation (2) corresponds to the transfer function of a lowpass filter, equation (3) corresponds to the transfer function of a highpass filter, equation (4) corresponds to the transfer function of a notch filter, and equation (5) corresponds to the transfer function of an allpass filter.

From (1)-(5), one can see that the parameters $\omega_{o}^{2}$ and $\omega_{o} / Q_{o}$ of the proposed voltage-mode filter realizations are given by

$\omega_{o}^{2}=g_{m} / C_{1} C_{2} R_{1}$

and

$\frac{\omega_{o}}{Q_{o}}=1 / C_{1} R_{1}$

From (6) and (7), one can see that the parameters $\omega_{o}$ and $\omega_{o} / Q_{o}$ can be adjusted by tuning the grounded resistor $R_{1}$. Moreover, $\omega_{o}$ can be adjusted by tuning $g_{m}$ without disturbing $\omega_{o} / Q_{o}$. And since $g_{m}$ is a function of $I_{A B C}$, this opens the way for current/voltage control of the parameter $\omega_{o}$.

\section{SENSITIVITY ANALYSIS}

By defining the passive sensitivity of a parameter $F$ to the element of variation $x_{i}$ by

$S_{x_{i}}^{F}=\frac{d F}{d x_{i}} \frac{x_{i}}{F}$, 
it is easy to show that the sensitivity of the parameters $\omega_{o}$ and $\omega_{o} / Q_{o}$ to the variations in passive elements are given by

$$
\begin{gathered}
S_{C_{1}}^{\omega_{o}}=S_{C_{2}}^{\omega_{o}}=S_{R_{1}}^{\omega_{o}}=-\frac{1}{2} \\
S_{C_{1}}^{\omega_{o} / Q_{o}}=S_{R_{1}}^{\omega_{o} / Q_{o}}=-\frac{1}{2}
\end{gathered}
$$

Similarly, the temperature-sensitivity of $\omega_{o}$ can be expressed by

$$
S_{T}^{\omega_{o}}=-\frac{1}{2}
$$

Thus, the $\omega_{o}$ and $\omega_{o} / Q_{o}$ sensitivities to passive-elements and temperature are low.

\section{SIMULATION RESULTS}

To verify the theoretical analysis, the proposed circuit has been simulated using Pspice. The CCII \pm has been simulated using the simplified nonideal model shown in Fig. 2(a) [18] with $C_{y}=1 p F, C_{z}=1.5 p F, R_{y}=20 M \Omega, R_{z}=2 M \Omega, R_{x y}=50 \Omega, h_{1}=h_{2}$ $=1.0$.

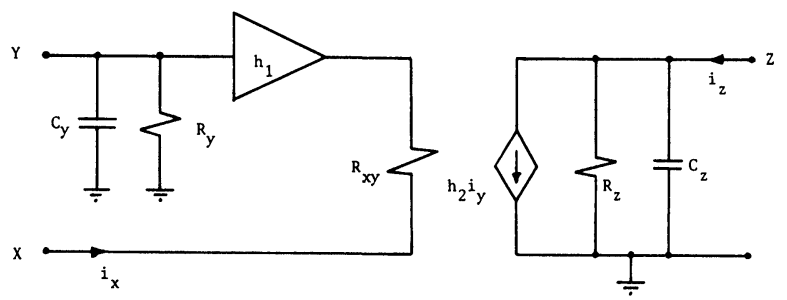

(a)

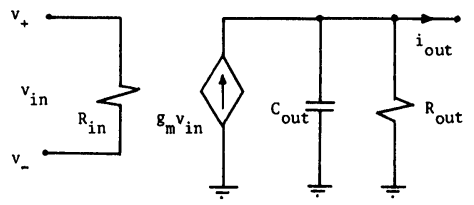

(b)

FIGURE 2 (a) Nonideal model for the current conveyor CCII+ and (b) Nonideal model for the OTA. 
The OTA has been simulated using the simplified model shown in Fig. 2(b) with $R_{\text {input }}=5 M \Omega, R_{\text {output }}=10 M \Omega, C_{\text {output }}=1 p F, g_{m}=1 \mathrm{~mA} / \mathrm{V}$.

With $R_{1}=1 k \Omega, R_{3}=R_{4}=R_{5}=R_{6}=R_{7}=R_{8}=R_{9}=10 \mathrm{k} \Omega, C_{1}=C_{2}=10 \mathrm{nF}, C_{3}=$ $1 n F$, the results obtained from the LPF, HPF, BPF, APF and the notch filter are shown in Fig. 3. These results are in good agreement with the theory presented.
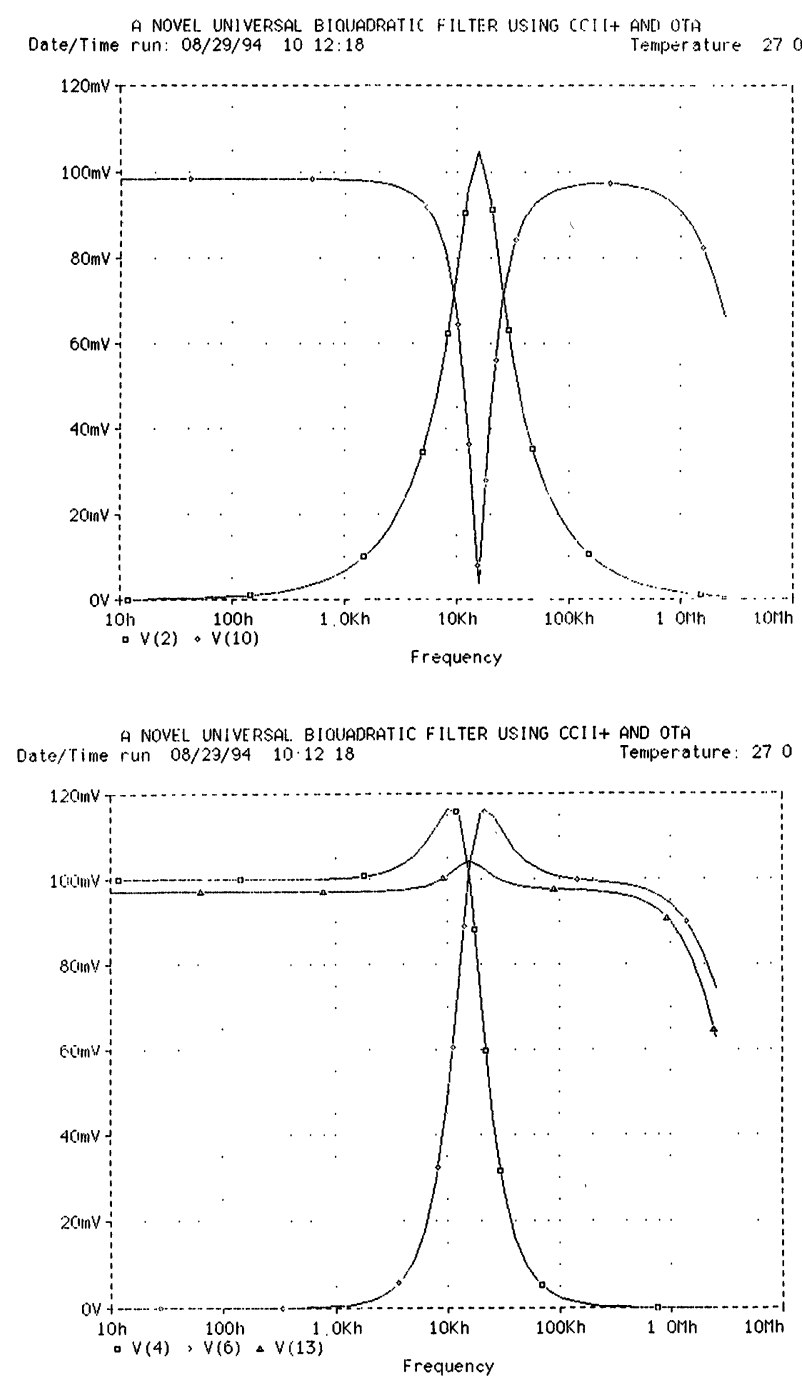

FIGURE 3 (a) Simulated bandpass and notch characteristics and (b) Simulated lowpass, highpass and allpass characteristics obtained from Fig. 1. 


\section{CONCLUSION}

In this paper, a novel universal programmable voltage-mode active filter using current conveyors has been presented. The circuit uses six current conveyors and one operational transconductance amplifier (OTA) and can simultaneously realize all the five standard biquadratic filter sections, the lowpass, the highpass, the bandpass, the allpass, and the notch. Values of $\omega_{o}$ can be adjusted by tuning the transconductance of the OTA without disturbing $\omega_{o} / Q_{o}$. This opens the way to programmable voltage(current)-control of the parameter $\omega_{o}$.

\section{REFERENCES}

1. C.-M. Chang, Novel universal current-mode filter with single input and three outputs using only five current conveyors, Electronics Letters, Vol. 29, 1993, pp. 2005-2007

2. C.-M. Chang, Universal active current filter with single input and three outputs using CCIIs, Electronics Letters, Vol. 29, 1993, 1932-1933

3. C.-M. Chang and P.-C. Chen, Universal active current filter with three inputs and one output using current conveyors, International Journal of Electronics, Vol. 71, 1991, pp. 817-819

4. C.-M. Chang, and P.-C. Chen, Realization of current-mode transfer function using secondgeneration current conveyors, International Journal of Electronics, Vol. 71, 1991, pp. 809-815

5. Y. Sun and J.K. Fidler, Versatile active biquad based on second-generation current conveyors, International Journal of Electronics, Vol. 76, 1994, pp. 91-98

6. C.-M. Chang, C.-C. Chien and H.-Y. Wang, Universal active current filter with three inputs using current conveyors-Part 2, International Journal of Electronics, Vol. 76, 1994, pp. 87-89

7. C.-M. Chang, Current-mode lowpass, bandpass and highpass biquads using two CCIIs, Electronics Letters, Vol. 29, 1993, pp. 2020-2021

8. C.-M. Chang, Universal active current filters using single second-generation current conveyor, Electronics Letters, Vol. 27, 1991, pp. 1614-1617

9. C.-M. Chang, C.-C. Chien and H.-Y. Wang, Universal active current filters using single secondgeneration current conveyor, Electronics Letters, Vol. 29, 1993, pp. 1159-1160

10. D.-S. Wu, Y.-S. Hwang, S.-I. Liu and Y.-P. Wu, New multifunction filter using an inverting CCII and a voltage follower, Electronics Letters, Vol. 30, 1994, pp. 551-552

11. C.-M. Chang and P.-C. Chen, Universal active filter with current gain using OTAs, International Journal of Electronics, Vol. 71, 1991, pp. 805-808

12. R. Nawrocki and U. Klein, New OTA-capacitor realisation of a universal biquad, Electronics Letters, Vol. 22, 1986, pp. 50-51

13. C. Toumazou and F.J. Lidgey, Universal active filter using current conveyors, Electronics Letters, Vol. 22, 1986, pp. 662-664

14. J. Wu, C.-Y. Xie, New multifunction active filter using OTAs, International Journal of Electronics, Vol. 74, 1993, pp. 235-239

15. V.K. Singh and R. Senani, New multifunction active filter configuration employing current conveyors, Electronics Letters, Vol. 26, 1990, pp. 1814-1816

16. S.-I. Liu and H.-W. Tsao, The single CCII biquads with high input impedance, IEEE Transactions on Circuits and Systems, Vol. 38, 1991, pp. 456-461

17. C.-M. Chang and M.-S. Lee, Universal voltage-mode filter with three inputs and one output using three current conveyors and one voltage follower, Electronics Letters, Vol. 30, 1994, pp. 2112-2113

18. B. Wilson, Performance analysis of current conveyors, Electronics Letters, Vol. 25, 1989, pp. 1596-1598 

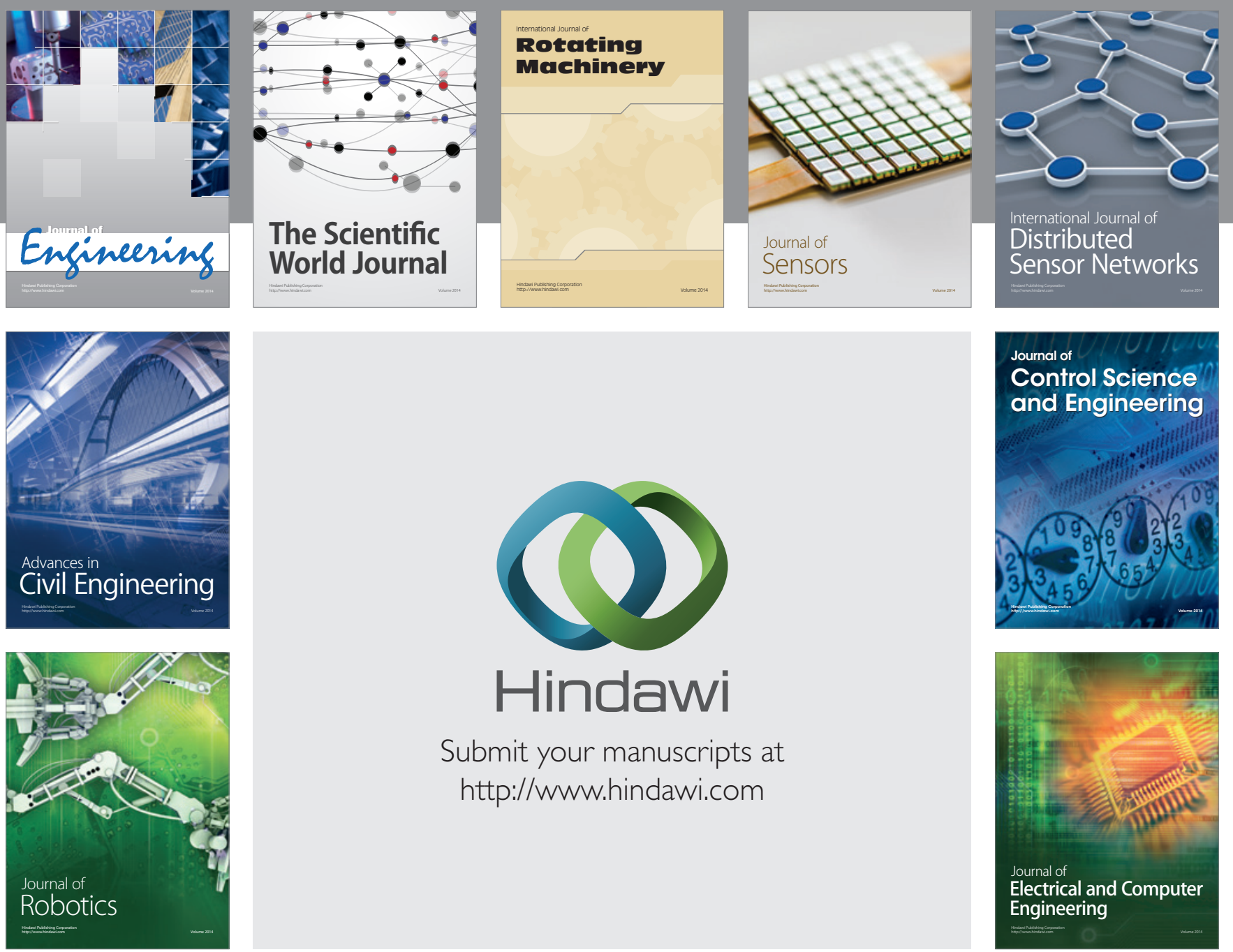

Submit your manuscripts at

http://www.hindawi.com
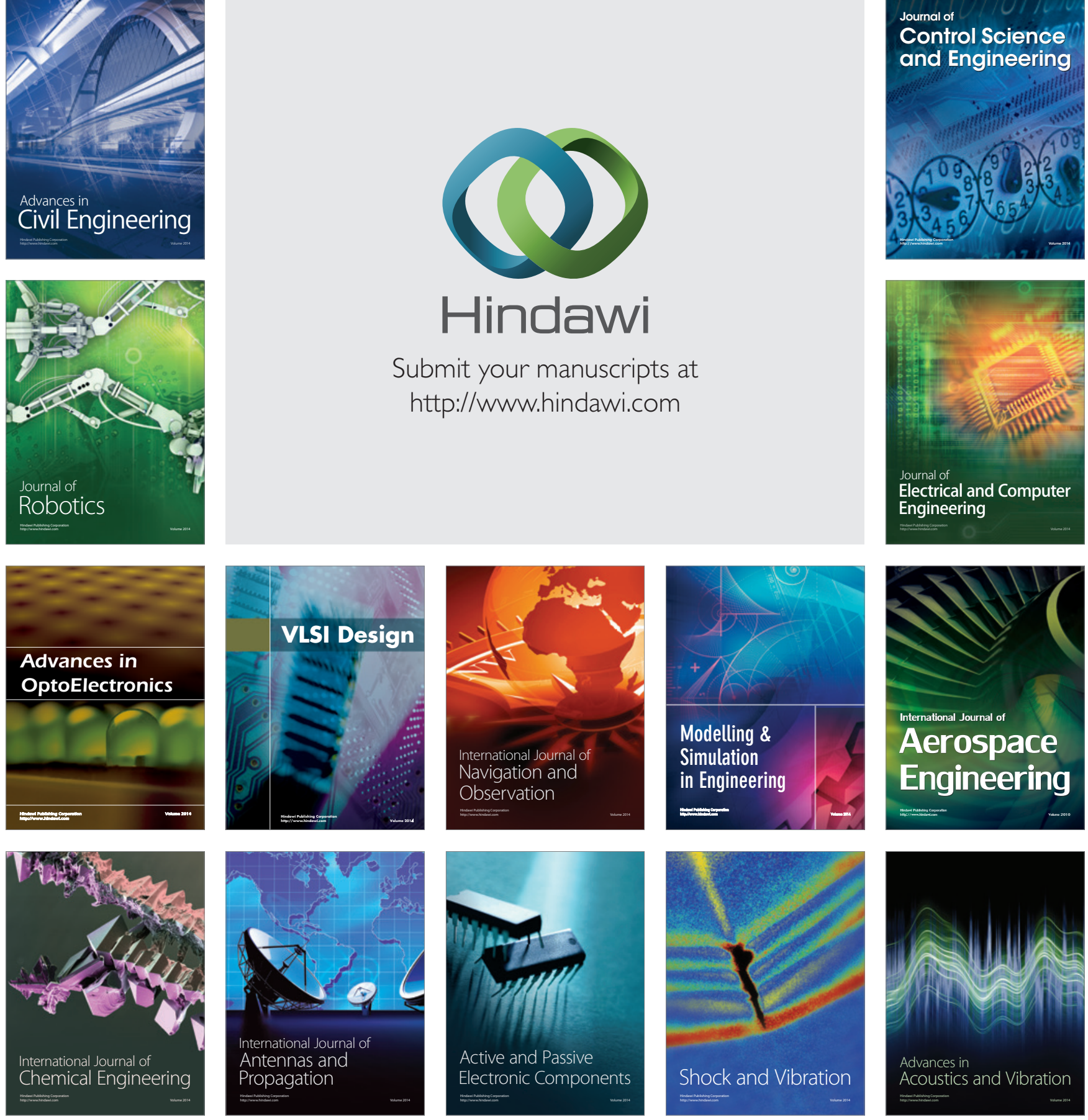